\title{
Electrochemical oxidation effect of ascorbic acid on mercury ions in blood sample using cyclic voltammetry
}

\author{
Muhammed Mizher Radhi ${ }^{1}$ (D) Hanaa Naji Abdullah ${ }^{1} \cdot$ Sura A. Al-Asadi ${ }^{1} \cdot$ \\ Emad A. Jaffar Al-Mulla ${ }^{2}$
}

Received: 12 June 2015/ Accepted: 5 September 2015/Published online: 15 September 2015

(c) The Author(s) 2015. This article is published with open access at Springerlink.com

\begin{abstract}
A modification glassy carbon electrode was fabricated as biosensors by mechanical attachment with carbon nanotubes to detect the effect of different concentrations of ascorbic acid (AA) on mercury ions in blood of human healthy samples using cyclic voltammetric technique. The oxidation potential peak of mercury ions in blood medium was appeared at $0.2 \mathrm{~V}$, while the same peak in $\mathrm{KCl}$ as a supporting electrolyte appeared at $0.25-0.3 \mathrm{~V}$. It was observed that the different concentrations of $\mathrm{AA}$ which are added to the mercury ions enhanced the oxidation current peak by raising the formation of decomposition complex in blood composition. This phenomenon appears while using seafood with lemon juice (as AA) which leads to the death if the percentage of mercury ions in the seafood was high. AA with mercury ions in blood media works as electrocatalysis by enhancing the oxidation current peak of mercury ions. It was very important to use the biosensor in the higher indicating analysis of the decomposition of the damage blood with higher sensitivity.
\end{abstract}

Keywords Ascorbic acid - Mercuric ion - Blood medium - Oxidative peaks - Cyclic voltammetry $\cdot$ CNT

Muhammed Mizher Radhi

mmrradhi@yahoo.com; mmradhi@yahoo.com

$\triangle$ Emad A. Jaffar Al-Mulla

imad.almulla@uokufa.edu.iq

1 Department of Radiological Techniques, College of Health and Medical Technology, Middle Technical University, Baghdad, Iraq

2 Department of Chemistry, Faculty of Science, University of Kufa, P.O. Box 21, An-Najaf 54001, Iraq

\section{Introduction}

Many electrochemical scientists studied the effect of the redox current peaks of mercury ions in different medium and different solid electrodes with nanomaterials by cyclic voltammetric technique [1-4].

Electrochemical methods provide high potential for the investigation of antioxidant compounds, assessment of antioxidant capacity, and measurement of electrochemical index. The devices can be stationary or flow through, and based on cyclic or differential pulse voltammetry as well as potentiostatic analysis. The methods are known for their suitability for food control and monitoring the levels of antioxidant capacity in other biological samples and matrices. The application of electrochemical methods for the analysis of plant and clinical samples with respect to study of their antioxidant properties was studied by different researchers [5].

The electrochemical behavior of ascorbic acid (AA) was studied by a description of the potentiometric, voltammetric and amperometric methods for vitamin $\mathrm{C}$ content estimation in various media. Different methods for the development of electrochemical sensors are used, from unmodified electrodes to different composites incorporating carbon nanotubes (CNTs), ionic liquids or various mediators. The interaction between the functional groups of the sensor's material and the analyte molecule is essential for the analytical characteristics obtained. The numerous applications of AA electrochemical sensors in fields like food, pharmaceutical or clinical analysis are a key of analyte [6].

Mercury is reported as a heavy metal that induces blood disorders and immunological effects. This study was performed to determine the haematological toxicity of mercury evaluated the protective antioxidant role of vitamin $\mathrm{C}$. 

oxidation current peak of $10 \mathrm{mM} \mathrm{Hg}$ (II) in $0.1 \mathrm{M} \mathrm{KCl}$ effected by the different concentrations of ascorbic acid (a) without AA, (b) $1 \mathrm{mM} \mathrm{AA}$, (c) $2 \mathrm{mM}$ AA, and (d) $3 \mathrm{mM}$ AA (using GCE/CNT, $100 \mathrm{mV} \mathrm{s}^{-1}$ vs. $\left.\mathrm{Ag} / \mathrm{AgCl}\right)$
Fig. 1 Voltammograms of

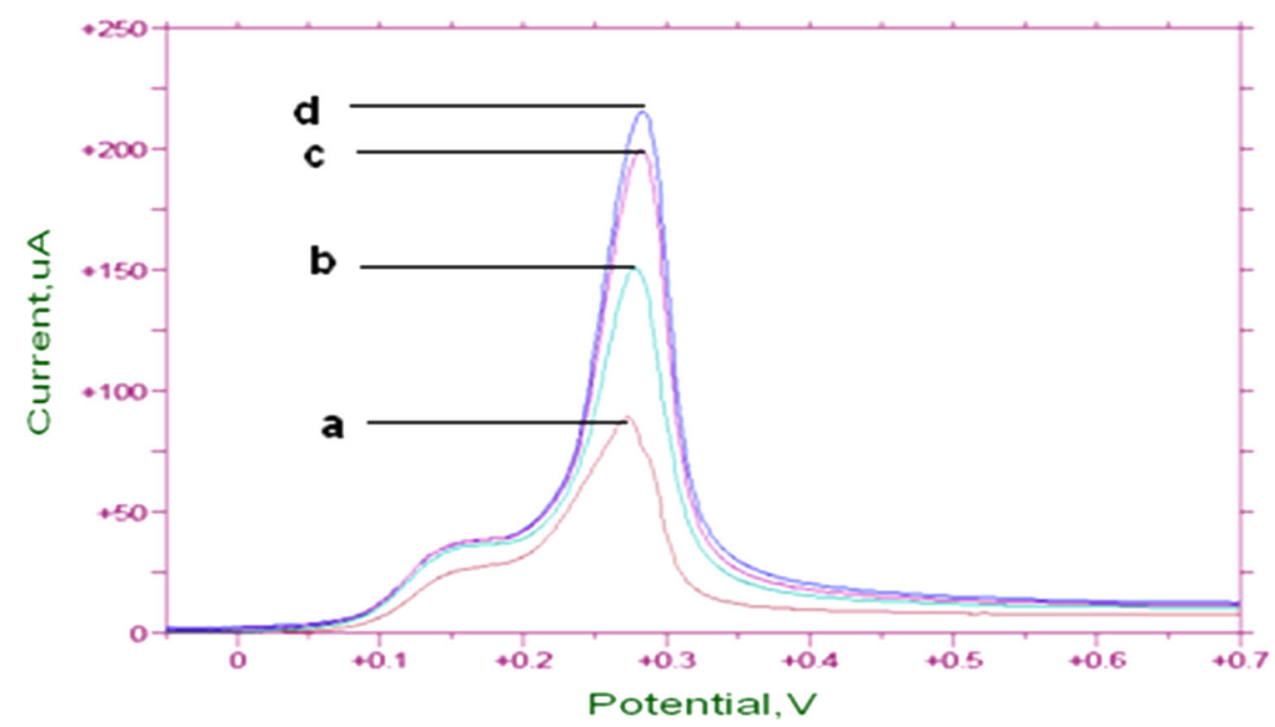

Fig. 2 Cyclic voltammogram of the oxidation current peak of $10 \mathrm{mM} \mathrm{Hg}^{2+}$ in $0.1 \mathrm{M} \mathrm{KCl}$ (using GCE, $100 \mathrm{mV} \mathrm{s}^{-1}$ vs. $\mathrm{Ag} / \mathrm{AgCl})$

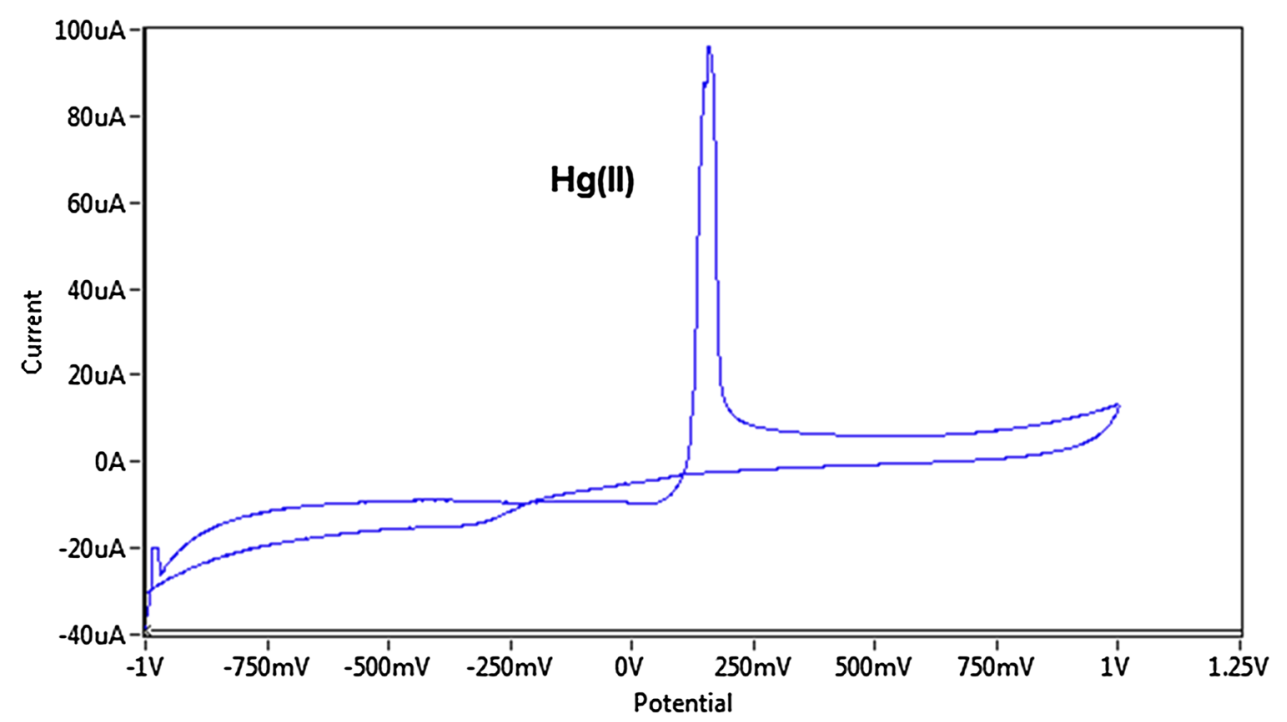

Studies have shown that vitamin $\mathrm{C}$ supplementation has varied effects on induced toxicity. AA has been found to interact with several elements in such a way as to render them less available for animals. The final results of this study of mercury and vitamin $\mathrm{C}$ had a protective effect on the potential harmful metals [7].

The studies are made to find therapeutic agents capable of minimizing genotoxicity of various natural and manmade compounds. The genotoxicity induced by mercury compounds remains controversial. It was found that the genotoxic effect of mercuric chloride at three concentrations (1.052, 5.262, and $10.524 \mu \mathrm{M}$ ) and AA (vitamin C) at a concentration of $9.734 \mu \mathrm{M}$ on mercuric chloride-treated short-term human leucocyte cultures. The results showed that mercury ions have no effect on cell-cycle kinetics. $\mathrm{Hg}$ (II) also significantly induced $\mathrm{C}$-anaphases (abnormal mitosis) in blood cultures. These effects were prevented by the addition of vitamin $\mathrm{C}$ to mercuric chloride-treated cultures. The data indicate that the mutagenic activity of mercuric chloride and the protective role of vitamin $\mathrm{C}$ on mercury-induced genotoxicity in human blood cultures is probably due to its strong antioxidant and nucleophilic nature [8].

Other study that the protective effects of vitamin $\mathrm{C}$ and vitamin $\mathrm{E}$ against mercuric chloride-induced reproductive toxicity and the mechanisms underlying these effects. The results provide further insight into the mechanisms of mercuric chloride-induced reproductive toxicity and confirm the antioxidant potential of both vitamin $\mathrm{C}$ and vita$\min \mathrm{E}[9]$.

MWCNT/TiO 2 composite was modified onto glassy carbon electrode (GCE) and fabricated by mechanical attachment, then applied to detection of AA using cyclic voltammetry (CV). The electrocatalytic study of AA using 
Fig. 3 Voltammograms of the oxidation current peak of $10 \mathrm{mM} \mathrm{Hg}^{2+} 0.1 \mathrm{M} \mathrm{KCl}$ and $100 \mathrm{mV} \mathrm{s}^{-1}$ vs. $\left.\mathrm{Ag} / \mathrm{AgCl}\right)$ $10 \mathrm{mM}$ AA (using GCE,

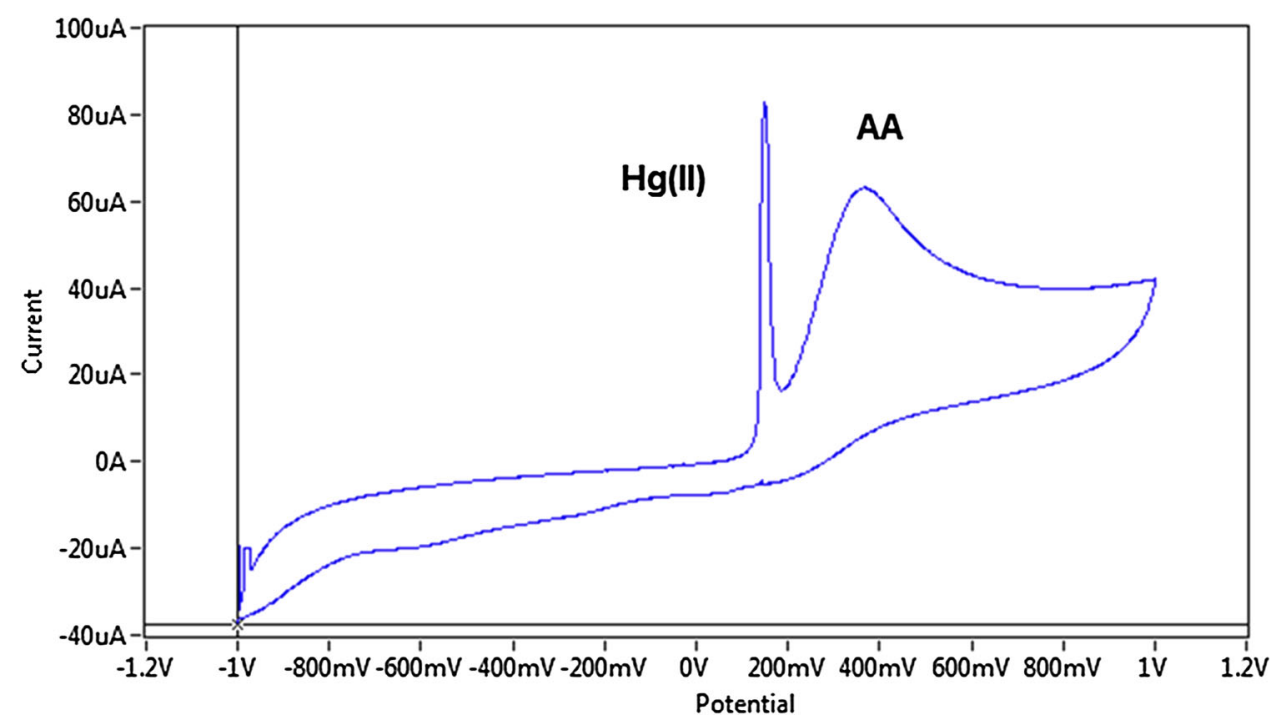

Fig. 4 Voltammograms for effect of AA in the oxidation current peaks of $1 \mathrm{mM} \mathrm{Hg}^{2+}$ in $0.1 \mathrm{M} \mathrm{KCl}$ (using GCE/CNT, $100 \mathrm{mV} \mathrm{s}^{-1}$ vs. $\left.\mathrm{Ag} / \mathrm{AgCl}\right)$

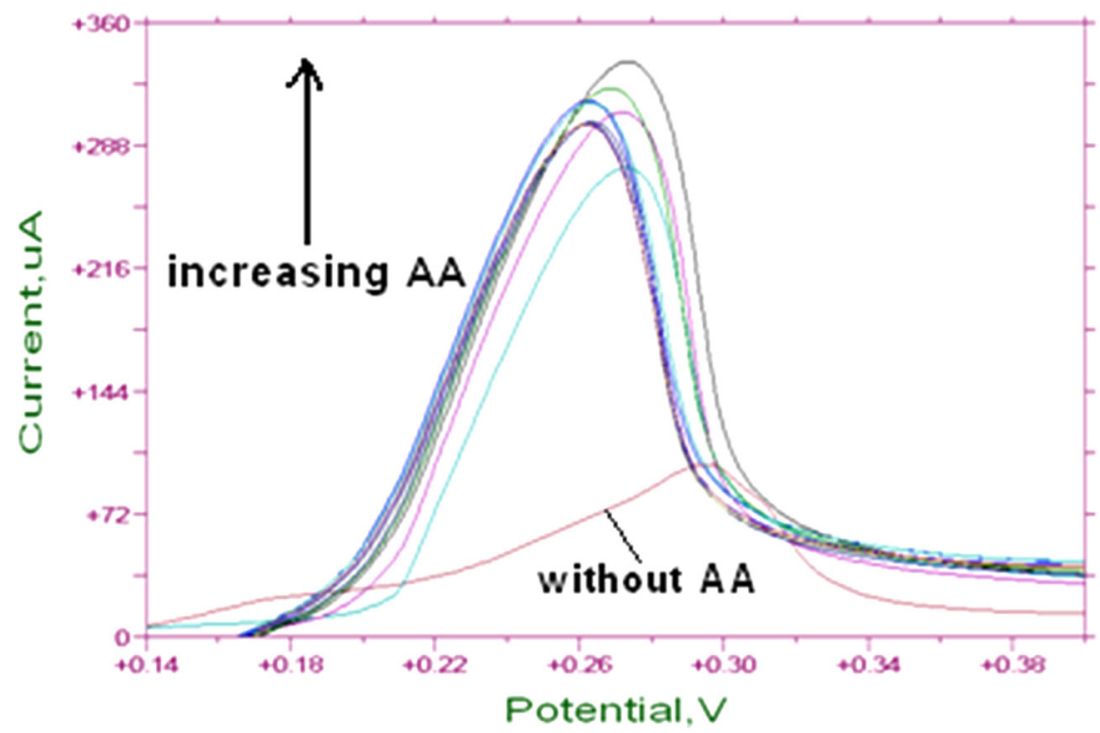

single-walled CNT/tungsten oxide ( $\left.\mathrm{SWCNT} / \mathrm{WO}_{3}\right)$-modified GCE prepared by mechanical attachment was conducted. The oxidation peaks obtained indicate that the SWCNT/ $/ \mathrm{WO}_{3}$-modified GCE has good electrochemical behavior in terms of sensitivity [10,11].

The present work involves studying of the biosensors as a good catalyst for the electro-analysis of the interference of mercuric ion with ascorbic ion and effected on the blood medium by cyclic voltammetric technique.

\section{Materials and methods}

CNT (Fluka, $98 \%$ ), blood samples were used from healthy human. Other chemicals and solvents were of annular grade and used as received from the manufacturer.
Deionized water was used for the preparation of aqueous solutions. All solutions were deaerated with oxygen free nitrogen gas for $10-15 \mathrm{~min}$ prior to making the measurement.

\section{Instruments}

Two types of instruments were used in this work; the first one is electrochemical workstations of Bioanalytical System, Inc., USA: models BAS CV 50W with potentiostat driven by electroanalytical measuring software were connected to personal computer to perform CV. The other one of instrument is EZstat series (potentiostat/galvanostat) NuVant Systems, Inc. pioneering electrochemical technologies USA. Electrochemical workstations of Bioanalytical System, Inc. with potentiostat driven by electroanalytical measuring 
Fig. 5 Cyclic voltammograms of the oxidation current peak of $0.1 \mathrm{M} \mathrm{Hg}^{2+}$ in mix of blood medium and $0.1 \mathrm{M} \mathrm{KCl}$ (using GCE, $100 \mathrm{mV} \mathrm{s}^{-1}$ vs. Ag/ $\mathrm{AgCl})$

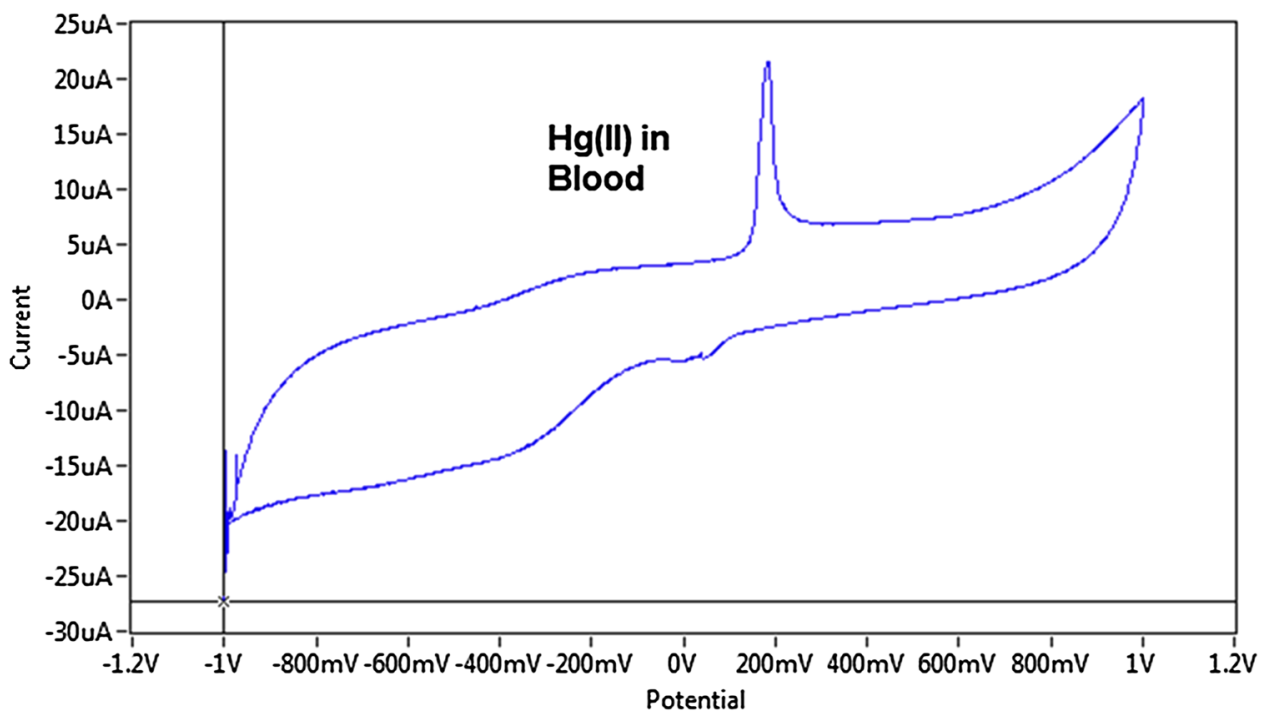

Fig. 6 Cyclic voltammogram of the oxidation current peak of $10 \mathrm{mM} \mathrm{Hg}^{2+}$ in mix of blood medium with $0.1 \mathrm{M} \mathrm{KCl}$ and $1 \mathrm{mM}$ AA (using GCE, $100 \mathrm{mV} \mathrm{s}^{-1}$ vs. $\mathrm{Ag} / \mathrm{AgCl}$ )

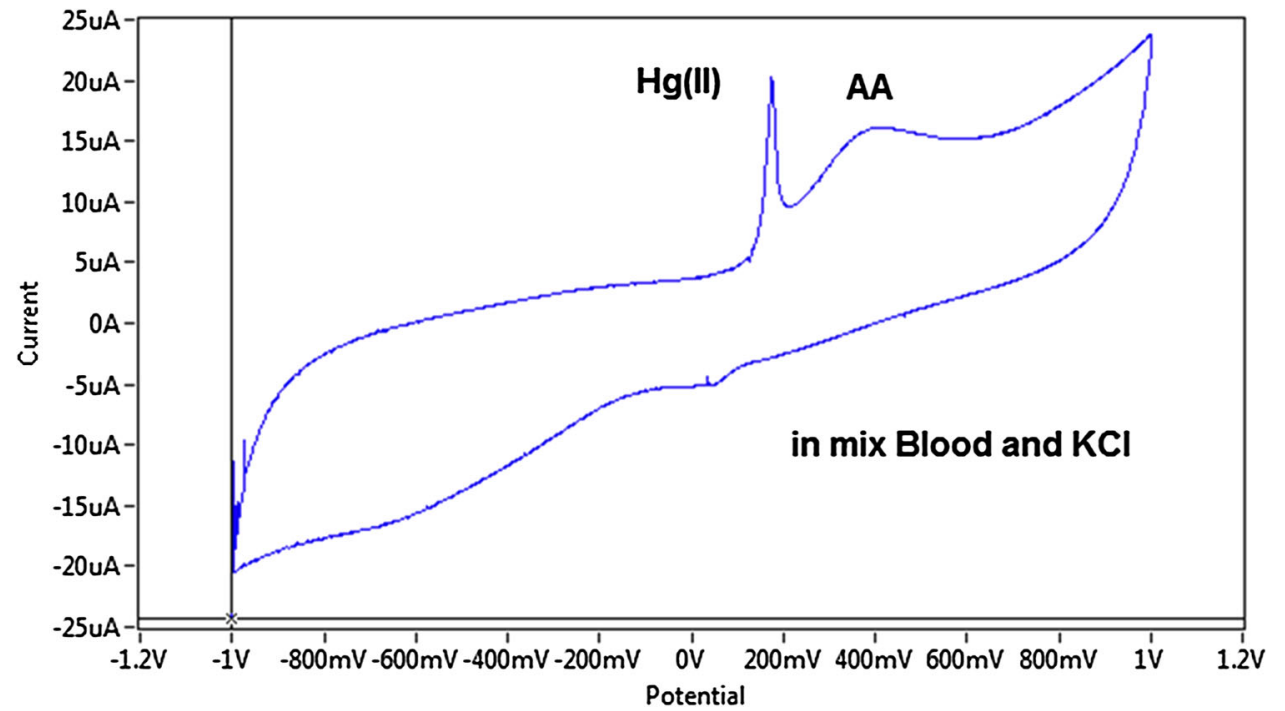

softwares were connected to personal computer to perform $\mathrm{CV}$; the $\mathrm{Ag} / \mathrm{AgCl}(3 \mathrm{M} \mathrm{NaCl})$ and platinum wire $(1 \mathrm{~mm}$ diameter) were used as a reference and counter electrode, respectively. The working electrodes used in this study were GCE and modified with CNT to present CNT/GCE by mechanical attachment method [12].

\section{Preparing for CNT modified GCE}

A mechanical attachment technique method [13, 14] used direct attachment (about thirty times) of CNT in powder form and modified GCE by abrasively adhere CNT nanoparticles onto the GCE surface. The modification of GCE was done every run of CV to avoid dropping of CNT from the surface of GCE into the solution of cell.

\section{Results and discussion}

\section{Effect of ascorbic acid}

Figure 1 shows the effect for the oxidation current peaks of $\mathrm{Hg}^{2+}$ with and without AA on modified GCE/CNT working electrode using $\mathrm{CV}$. It was observed that the oxidation peak of $\mathrm{Hg}^{2+}$ appeared at $+260 \mathrm{mV}$. It was considerably enhanced by three-four times in the presence of $1 \mathrm{mM} \mathrm{AA}$, five-seven times in $2 \mathrm{mM} \mathrm{AA}$, and six-eight times in $3 \mathrm{mM}$ AA.

It was found that mercuric ions exhibit oxidizing agent behavior when used in acidic media such as AA solution which enhances the oxidation current peak at $\mathrm{CV}$ analytic study as shown in Figs. 2 and 3. 
Fig. 7 Cyclic voltammogram of the oxidation current peak of $10 \mathrm{mM} \mathrm{Hg}^{2+}$ in mix of blood medium with $0.1 \mathrm{M} \mathrm{KCl}$ and $10 \mathrm{mM}$ AA (using GCE, $100 \mathrm{mV} \mathrm{s}^{-1}$ vs. $\left.\mathrm{Ag} / \mathrm{AgCl}\right)$

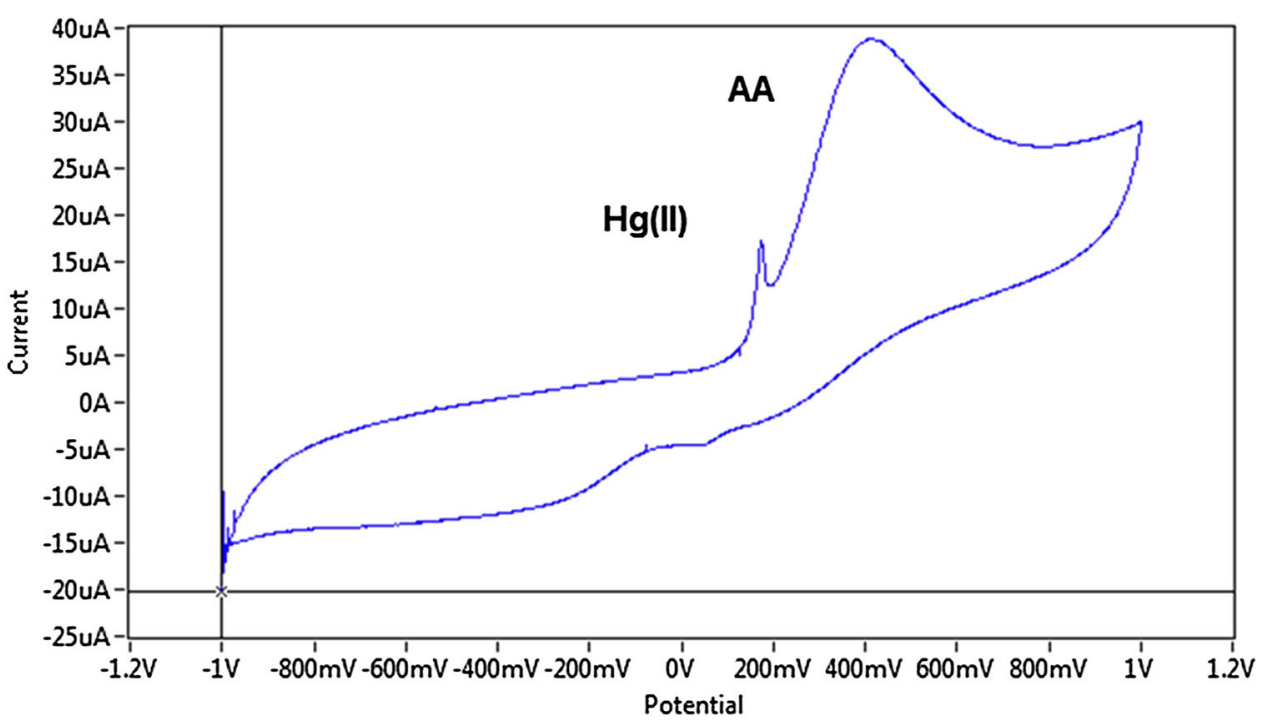

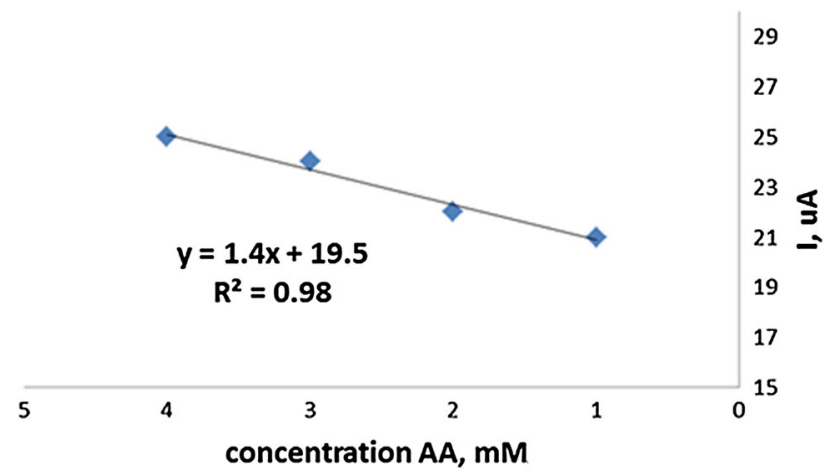

Fig. 8 Plot of oxidation current versus different concentrations of AA (1-4 mM) in blood medium with $10 \mathrm{mM} \mathrm{HgCl}_{2}$ and $0.1 \mathrm{M} \mathrm{KCl}$ using $\mathrm{GCE}$ versus $\mathrm{Ag} / \mathrm{AgCl}$

\section{Effect of lower pH (acidity AA)}

The effect of acidic solution at lower $\mathrm{pH}$ using AA solution on $\mathrm{Hg}(\mathrm{II})$ with $\mathrm{KCl}$ as supporting electrolyte. It was observed that the oxidation current of $\mathrm{Hg}^{2+}$ gradually increases linearly with lowering of $\mathrm{pH}$ from 6 to 2 accompanied by linear shift in oxidation potential, $E(\mathrm{mV})=-5.546 \mathrm{pH}+224.09$ with correlation coefficient of $R^{2}=09267$ and $I(\mu \mathrm{A})=1.646 \mathrm{pH}-0.7637$ with correlation coefficient of $R^{2}=0.9844$; the oxidation peak increased in about twofolds and shifting toward origin potential [1] as shown in Fig. 4.

\section{Effect of AA on $\mathrm{Hg}(\mathrm{II})$ in blood medium}

In this study, the effect of AA on the high oxidative compounds such as $\mathrm{Hg}$ (II) in blood medium was studied using cyclic voltammetric technique. The danger lies in the case of a perimeter of an acid such as AA which works as electrocatalysis, so for its acidity media to enhance the oxidative current peak which causes blood to disintegrate and the formation of a complex leads to death.

Figure 5 illustrates high current peak of mercury ions in blood medium as an oxidative agent in human blood. The more danger is due to the presence of acidic $\mathrm{pH}$ like AA solution which enhances the oxidation current peak of $\mathrm{Hg}(\mathrm{II})$ as shown in Figs. 6 and 7.

\section{Effect of different concentrations of AA}

The calibration plot (Fig. 8) was performed at the GCE in $10 \mathrm{mM} \mathrm{Hg}^{2+}$ solutions with a good linearity of anodic current versus $\mathrm{Hg}^{2+}$ described by $Y=1.4 X+19.5, R^{2}=0.98$.

\section{Conclusion}

Voltammetric determination of $\mathrm{Hg}(\mathrm{II})$ ions in blood media was studied using modified GCE with and without modified CNT. The determination was based on the finding of the results of the oxidation current peak by cyclic voltammetric technique. The enhancement of oxidation current peak of $\mathrm{Hg}$ (II) in the presence of AA causes the decomposition and damage in blood composition. This contribution accentuates the role of electrochemical techniques in the determination of oxidant activity in the biological blood sample. Electrochemical techniques represent due to selectivity and sensitivity suitable tool for the determination of oxidant capacity in biological blood sample, where these methods are sensitive under the low concentrations of AA affected on the oxidation current peak of $\mathrm{Hg}(\mathrm{II})$. In addition, obtaining oxidation current peaks and their position enable us to estimate the possible oxidant agent present in a blood sample. These findings 
suggest that mercury present in the environment and in particular in foodstuffs especially in seafood of first necessity causes haematological disturbances in the blood composition.

Open Access This article is distributed under the terms of the Creative Commons Attribution 4.0 International License (http://crea tivecommons.org/licenses/by/4.0/), which permits unrestricted use, distribution, and reproduction in any medium, provided you give appropriate credit to the original author(s) and the source, provide a link to the Creative Commons license, and indicate if changes were made.

\section{References}

1. Radhi MM, Tan WT, Ab Rahman MZ, Kassim AB (2010) Electrochemical redox of $\mathrm{Hg}^{2+}$ mediated by activated carbon modified glassy carbon electrode. Int $\mathrm{J}$ Electrochem Sci 5:615-629

2. Radhi MM, Tan WT, Ab Rahman MZ, Kassim AB (2010) Voltammetric detection of $\mathrm{Hg}(\mathrm{II})$ at $\mathrm{C}_{60}$, activated carbon and MWCNT modified glassy carbon electrode. Res J Appl Sci 5:59-64

3. Radhi MM, Al-Mulla EAJ (2015) Use of a grafted polymer electrode to study mercury ions by cyclic voltammetry. Res Chem Intermed 41:1413-1420

4. Tan WT, Radhi MM, Ab Rahman MZ, Kassim AB (2011) Application studies to voltammetric detection of trace $\mathrm{Hg}$ (II) by different modified solid glassy carbon electrode. Aust J Basic Appl Sci 5:2475-2481
5. Abdullah AA, Al-Mulla EAJ, Aowda SA (2013) Electrochemical studies of copper fatty amides complex in organic medium. Res Chem Intermed 39:2817-2823

6. Radhi MM, Al-Mulla EAJ, Hoiwdy WH (2013) Effect of temperature on frying oils: infrared spectroscopic studies. Res Chem Intermed 39:3173-3179

7. Mohammed IA, Abd Khadir NK (2014) New polyurethane nanocomposites based on soya oil. J Oleo Sci 63:193-200

8. Radhi MM, Al-Mulla EAJ (2014) Application study of grafted polymer electrode in manganese ions during cyclic voltammetry. Rend Lincei Scienze Fisiche E Naturali 25:209-213

9. Al-Shemmari FA, Rabah AA (2014) A comparative study of different surfactants for natural rubber clay nanocomposite preparation. Rend Lincei Scienze Fisiche E Naturali 25:409-413

10. Al-Mulla EAJ (2011) Lipase-catalyzed synthesis of fatty thioic acids from palm oil. J Oleo Sci 60:41-45

11. Yunus WMZ, Ibrahim NAB, Rahman MZA (2010) Difatty acyl urea from corn oil: synthesis and characterization. J Oleo Sci 59:157-160

12. Tan WT, Lim E, Bond A (2003) Voltammetric studies on microcrystalline $\mathrm{C}_{60}$ adhered to an electrode surface by solvent casting and mechanical transfer methods. J Solid State Electrochem 7:134-140

13. Al-Mulla EAJ (2011) Preparation of polylactic acid/epoxidized palm oil/fatty nitrogen compounds modified clay nanocomposites by melt blending. Polym Sci A 53:149-157

14. Issam AM, Al-Janabi KW (2015) A novel method for the synthesis of biodiesel from soybean oil and urea. C R Chim $18: 525-529$ 